\title{
A visualização espacial através da modelagem paramétrica e da fabricação digital em edifícios curvilíneos de Oscar Niemeyer no Memorial da América Latina
}

The spatial visualization through parametric modeling and digital fabrication in curvilinear buildings by Oscar Niemeyer in the Latin America Memorial

\author{
Breno Tisi Mendes da Veiga \\ Universidade Presbiteriana Mackenzie, Brasil \\ brenoveiga@hotmail.com \\ Wilson Florio \\ Universidade Presbiteriana Mackenzie / \\ Universidade Estadual de Campinas, Brasil \\ wflorio@uol.com.br
}

\begin{abstract}
This paper analyzes the geometry of three buildings designed by Oscar Niemeyer in the Latin America Memorial, the Hall of Acts Tiradentes, the Victor Civita Library and the Simón Bolívar Auditorium, through the use of parametric modeling, geometric modeling and rapid prototyping. This research comes to fill a gap in what concerns the lack of demonstration of the underlying geometry of Niemeyer's projects.
\end{abstract}

Keywords: Geometry; Parametric modeling; Rapid Prototyping; Oscar Niemeyer.

\section{Introdução}

Nas últimas décadas, há um renovado interesse por formas curvilíneas na concepção de formas em arquitetura, de geometria orgânica. Schumacher (2009) defende um estilo denominado por ele de "Parametricismo", que está "enraizado em refinamentos baseados em sistemas de modelagem paramétrica e por métodos de script".

A modelagem paramétrica (MP) na contemporaneidade tem provado seu valor como potencializador do intelecto do arquiteto e como instrumento projetual. O desenvolvimento de recursos de simulação, modelagem e scripting produziram novas formas, geometrias, interações, versões e designs do discurso arquitetônico.

A partir da leitura de Monedero (2000), Mark, Gross \& Goldschimidt (2008), Hudson (2010) e Woodburry (2010), é possível definir modelagem paramétrica como a modelagem de uma geometria, a partir da definição de um conjunto de regras ou parâmetros. É fundamentada na lógica das relações associativas e de dependência entre seus objetos e no relacionamento entre a parte com o todo, onde a simples variação de parâmetros acarreta na criação de uma família de formas.

Diferente da modelagem paramétrica, a modelagem geométrica (MG) não se apropria de algoritmos paramétricos para criar uma variedade de resultados. Segundo Rego (2008), "a modelagem geométrica recorre às regras formais da geometria clássica e aos recursos da topologia para elaboração dos modelos de objetos com formas bem definidas" (p. 77). A MG é editável apenas por meio das ferramentas de edição do próprio programa, como operações booleanas de adição, subtração, intersecção ou divisão.

A fabricação digital (FD) pode ser definida como um grupo de processos auxiliado por diferentes tecnologias computacionais que manipulam ou deformam diferentes materiais (Seely, 2000). Os diferentes métodos empregados auxiliaram no entendimento da tectônica da forma e na percepção do espaço arquitetônico, como observado em (Sass \& Oxman, 2006).

Há diversas pesquisas realizadas sobre obras do arquiteto Oscar Niemeyer. A grande maioria examina aspectos gerais (Papadaki, 1950; Katinsky, 1990; Valle, 2000; Corona, 2001; Segre, 2008; Philippou, 2008). Porém, são poucas as que examinam o Memorial da América Latina (Zein, 2007; Ohtake, 2007; Underwood, 2010; Lemos, 2013), e raras as que exploram a geometria subjacente de edifícios curvilíneos (Mayer, 2003). Consequentemente, o problema identificado é que não há estudos sistemáticos sobre a definição geométrica das formas curvilíneas nas três obras analisadas de Oscar Niemeyer.

Foi observado que ainda existe uma lacuna no estudo sistemático da obra de Niemeyer que permita explicitar a geometria subjacente de seus projetos. Assim, a presente pesquisa (Veiga, 2016), realizada entre 2014 e 2016, empregou as tecnologias de MP, MG e FD (corte a laser, CNC, FDM e SLS) como método exploratório para a análise da geometria de projetos do arquiteto. 
Este artigo propõe demonstrar a geometria subjacente de três edifícios projetados por Oscar Niemeyer no Memorial da América Latina: o Salão de Atos Tiradentes, a Biblioteca Victor Civita e o Auditório Simón Bolívar. Deste modo a contribuição original do artigo é o estudo da geometria decorrente deles, impetrada por meio do redesenho dos projetos originais, pela modelagem paramétrica, modelagem geométrica e por diferentes métodos de fabricação digital.

\section{Antecedentes}

A arquitetura de Niemeyer é dividida pelo próprio arquiteto em "fases": primeiros projetos; Pampulha; pós-Pampulha; Brasília; pós-Brasília e últimos projetos (Corona, 2001). O Memorial da América Latina foi projetado em 1988, se insere na fase "pós-Brasília" do arquiteto. Este conjunto é considerado por Underwood (2010) como uma síntese da busca por novas formas e relações espaciais em um conjunto arquitetônico dentro da cidade, onde o dinamismo visual é derivado do contraste entre diversos volumes geométricos.

Ohtake (2007) compara a distribuição espacial dos edifícios do Memorial, às bordas da grande praça de concreto, com as piazzas italianas. Porém, este autor cita que o projeto dos edifícios reflete um ideal moderno, onde cheios e vazios coexistem em harmonia.

Zein (2007) celebra a poética visual do Memorial e a variedade de suas formas. Segundo a autora, a grande praça central, rodeada pelas vigas-trave do Salão de Atos e da Biblioteca e a grande casca ondulada do auditório, remontam ao perfil das montanhas da Cantareira ao fundo.

Por outro lado, o arquiteto e professor Carlos Lemos (2013), que trabalhou com o arquiteto, critica os oposicionistas do Memorial, que analisam a obra somente sob o ponto de vista funcional que, segundo o autor, apela a um mal definido formalismo, a fim de se proferir uma condenação estética.

O projeto do Memorial da América Latina, desde sua concepção, ansiava pela grandiosidade de um centro cívico e cultural para um continente inteiro. Niemeyer criou uma síntese das artes plásticas com sua arquitetura, uma grande variedade de formas e curvas que, de maneira harmoniosa, compõe uma arquitetura plástica ao associar uma consciência da técnica construtiva com conhecimentos em artes plásticas e um repertório formal bastante desenvolvido.

Nota-se que o arquiteto readapta elementos formais no Memorial da América Latina de diferentes fases de sua carreira, desde as curvas do Conjunto Arquitetônico da Pampulha até a grandiosidade dos palácios de Brasília. Do esboço gestual do arquiteto, produziu um espaço que transcende os limites da cidade, devido à sua invenção arquitetural e seu simbolismo.

\section{Procedimentos metodológicos}

Os procedimentos metodológicos deste artigo se dividem em: i) a coleta de dados (CD); ii) o redesenho dos projetos dos edifícios (RE); iii) a modelagem paramétrica (MP); iv) a modelagem geométrica (MG); v) a análise geométrica (AG) e finalmente, diferentes tipos de fabricação digital: corte a laser, CNC (Computer Numeric Control), FDM (Fused Deposition Modeling) e SLS (Selective Laser Sintering), como observado na Figura 1.

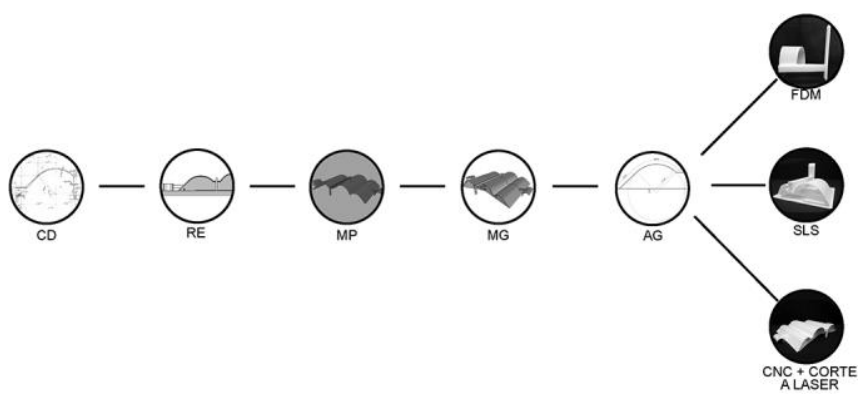

Figura 1: Procedimentos metodológicos. Fonte: Veiga \& Florio (2016).

\section{Coleta de Dados e Redesenho}

A coleta de dados (CD) se refere à obtenção de parte do projeto executivo dos três edifícios analisados. Cópias digitais dos desenhos da Construtora Promon, encarregada pela construção do Memorial, foram gentilmente cedidos pela Fundação do Memorial da América Latina. Ao todo foram cedidos 69 arquivos contendo desenhos do Salão de Atos, 124 arquivos da Biblioteca Victor Civita e 325 do Auditório Simón Bolívar.

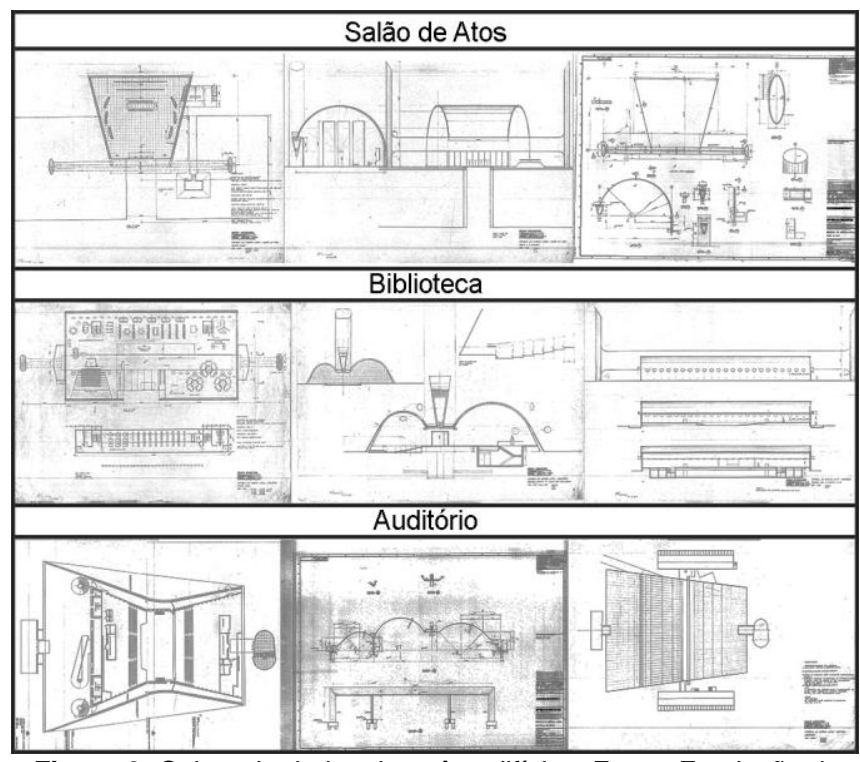

Figura 2: Coleta de dados dos três edifícios. Fonte: Fundação do Memorial da América Latina (2015).

É importante frisar que grande parte dos arquivos obtidos continham detalhes estruturais, plantas de instalações prediais, acabamentos, paisagismo, detalhamento de caixilharia, luminotécnica, paginação de piso, entre outros. 
Este artigo utilizou as plantas dos diferentes pavimentos, os cortes e as diferentes elevações de cada edifício como método investigativo. Parte dos desenhos utilizados são expostos na Figura 2. O método de coleta de dados serviu para obter as informações necessárias, a fim de transformálas em dados reveladores da geometria dos edifícios analisados.

Durante a etapa de redesenho (RE), parte dos desenhos técnicos (plantas, cortes e elevações) foram redesenhados utilizando programa AutoCad para facilitar a análise da geometria dos edifícios e também padronizá-la, garantindo o mesmo peso gráfico aos desenhos.

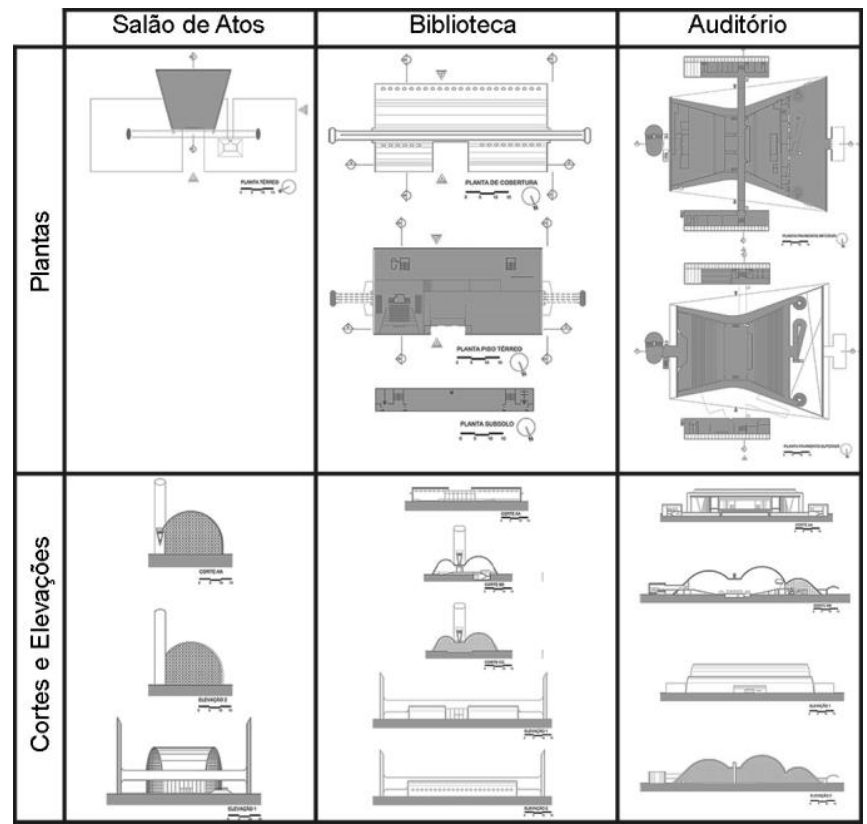

Figura 3: Redesenho dos desenhos técnicos dos três edifícios. Fonte: Veiga (2016).

A Figura 3 retrata os diferentes redesenhos produzidos. Observa-se que a quantidade de redesenhos é proporcional à complexidade formal do edifício. Por essa razão o Salão de Atos Tiradentes apresenta uma quantidade menor de redesenhos em relação aos demais edifícios.

O redesenho dos projetos possibilitou um estudo primário das diversas dimensões estruturais dos diversos elementos dos edifícios e do espaço arquitetônico. Também possibilitou remover as informações não relevantes para este artigo, como por exemplo, informações sobre instalações prediais.

\section{Modelagem Paramétrica}

A modelagem paramétrica (MP) permitiu identificar os diversos arcos de circunferência e os segmentos de reta que compõem a geometria dos edifícios. O plug-in Grasshopper, junto com o Rhinoceros, facilitou a modelagem de geometrias curvilíneas complexas.

Uma das vantagens de se trabalhar com o Grasshopper é que o programa transforma scripts em peças visuais, chamadas de componentes. Esses componentes podem assumir a representação de geometrias como ponto, reta, circunferência ou fórmulas matemáticas de adição, subtração, multiplicação, etc.

Na Figura 4 se observa o algoritmo que produziu o modelo tridimensional dos edifícios, o processo de modelagem da casca de concreto e a modelagem finalizada.

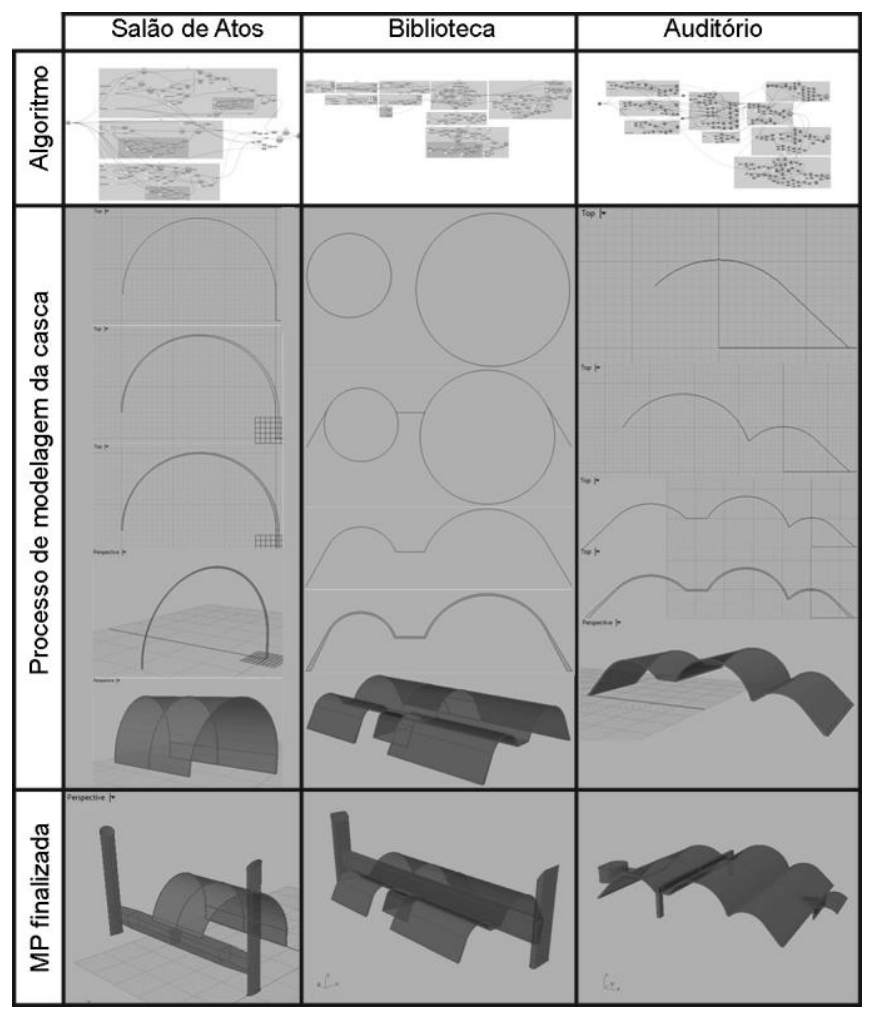

Figura 4: Algoritmo, processo de modelagem da casca e a MP dos três edifícios. Fonte: Veiga (2016).

A modelagem da casca de concreto dos três edifícios seguiu as dimensões observadas no redesenho. Observa-se na Figura 4 que o processo de modelagem foi o mesmo para todos os objetos. i) Primeiramente foram definidas as circunferências que compõem a geometria de cada cobertura; ii) em seguida foram definidos os pontos de apoio das cascas no solo; iii) foram estabelecidas as tangentes entre os pontos de apoio e as circunferências; iv) foi desenhada a espessura da casca; e por último, o desenho foi "extrudado" para criar um modelo tridimensional da casca.

A modelagem da viga aporticada e dos pilares seguiu o mesmo princípio de modelagem. A seção de cada elemento foi inicialmente modelada e posteriormente "extrudada".

\section{Modelagem Geométrica}

Após a modelagem paramétrica os modelos foram materializados para o Rhinoceros com o auxílio do comando Bake.

Os projetos analisados possuem uma geometria complexa. Contudo, parte de seus componentes são compostos por 
formas de geometria mais simples, por essa razão não foram modelados parametricamente.

Verificou-se uma dificuldade na interpretação e representação de espaços arquitetônicos formados por formas curvilíneas. Espaços não ortogonais que apresentam diversas dilatações e contrações em sua forma são difíceis de serem interpretados por meios de desenhos bidimensionais.
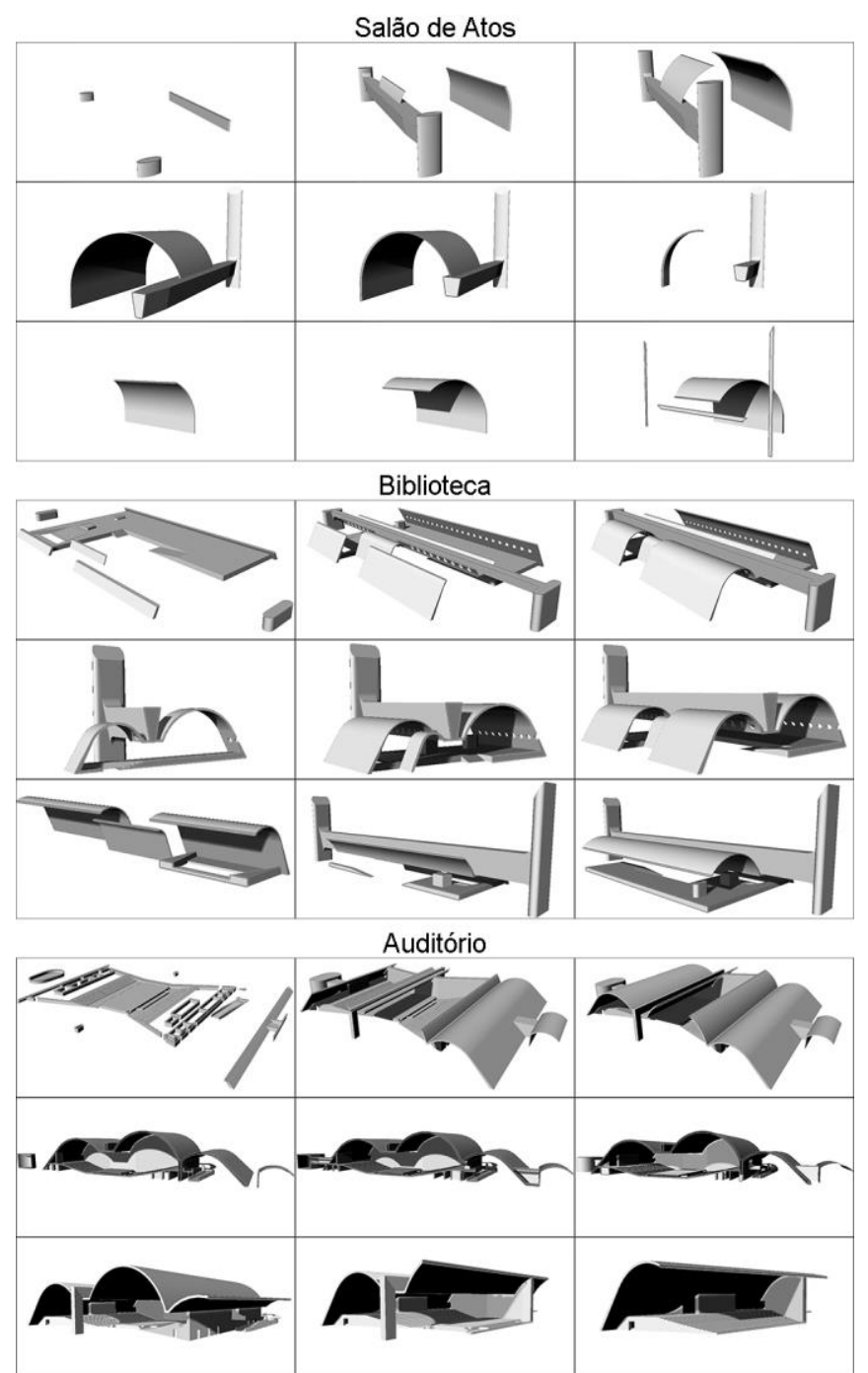

Figura 5: Modelagem Geométrica dos três edifícios. Fonte: Veiga (2016).

Foram modelados no Rhinoceros o interior dos edifícios, possibilitando a análise dos diversos espaços internos. A Figura 5 exibe diversos cortes perspectivados dos três edifícios analisados. É possível notar como que as diversas cascas se desenvolvem e observar as contrações e dilatações do espaço arquitetônico.

Esse tipo de representação tem como objetivo demonstrar o dinamismo espacial interno da obra. A tridimensionalidade do desenho perspectivado aproxima o observador do mundo tridimensional que o rodeia.
Notam-se algumas características fundamentais nos cortes apresentados na Figura 5. Nos desenhos do Salão de Atos se observa a variação da seção da viga e a variação da espessura da casca de concreto, que se desenvolve a partir de uma tangente perpendicular ao piso.

Nos outros dois edifícios, de geometria e espaço interno mais complexo, observa-se a nítida divisão do espaço interno de acordo com a geometria das abóbodas da cobertura.

Observa-se na Biblioteca uma divisão do espaço interno em duas partes: uma área de consulta do acervo de pé direito mais alto e o foyer. Divisão similar é observada no auditório onde as três abóbodas da cobertura marcam a divisão do espaço interno em três partes: foyer e as duas plateias.

Nota-se que existe uma preferência do arquiteto em localizar o acesso principal do edifício em uma zona de pé direito menor. Com essa escolha, Niemeyer estabelece uma zona receptiva no foyer da construção, uma transição entre o exterior e as dilatações do espaço interno.

\section{Análise Geométrica}

A análise geométrica (AG) permitiu revelar a geometria subjacente destas três obras de Niemeyer. Por meio deste tipo de análise foi possível demonstrar a composição de cada elemento que compõem a geometria dos edifícios analisados.

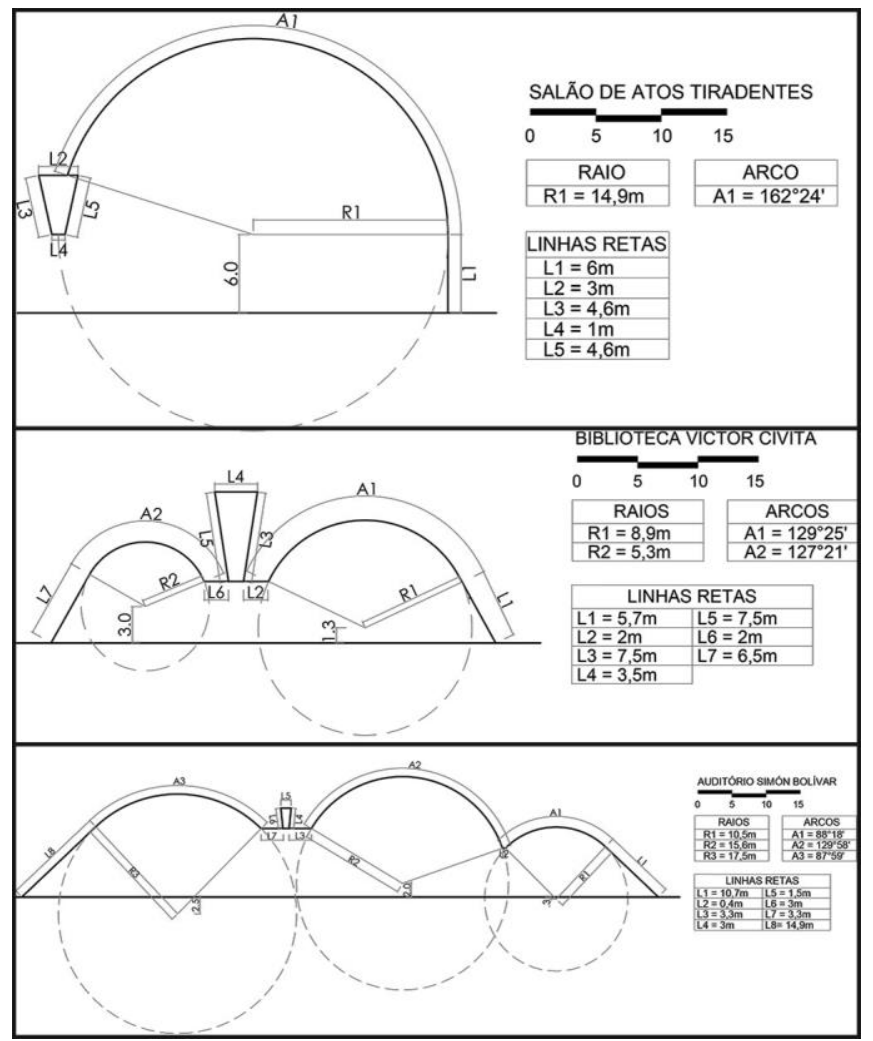

Figura 6: Análise Geométrica dos três edifícios. Fonte: Veiga (2016).

Como é possível notar na Figura 6, as dimensões de cada segmento de reta, raio e arco de circunferência foram 
explicitadas. Observa-se que a geometria dos edifícios estudados é resultante da alternância de elementos simples. Nessa figura cada linha reta está demarcada com a legenda (L), os arcos de circunferência com (A) e os raios das circunferências $(R)$. As circunferências geradoras da forma foram destacadas e desenhadas com o tracejado. Assim, a complexidade de sua forma é resultado da inteiração entre os diversos elementos que a compõe e os pontos de tangência.

É comum na arquitetura de Oscar Niemeyer projetos onde a forma construída apresenta uma geometria simples e o espaço arquitetônico exibe diversas contrações e dilatações, enriquecendo o caminhar pelo espaço projetado pelo arquiteto.

Nesta pesquisa, a análise geométrica possibilitou a decomposição da geometria em partes. Foi possível revelar as particularidades e pormenores da geometria dos edifícios analisados. Nota-se claramente que a simplicidade da forma externa dos edifícios analisados contrasta em relação à complexidade espacial interna.

\section{Fabricação Digital}

Protótipos são excelentes aliados no processo de projeto e análise de edifícios arquitetônicos. É possível entender com a materialização de um protótipo a concretude que esse tipo de artefato oferece ao processo de projeto.

Ao todo foram produzidos três modelos físicos, um para cada edifício analisado. Foram empregados métodos distintos de fabricação e de prototipagem. O Salão de Atos foi produzido com o auxílio de uma impressora FDM; a Biblioteca por uma impressora SLS; e o Auditório, o maior dos três modelos, foi produzido por uma união de duas técnicas: a subtrativa, com auxílio de uma fresadora CNC e a de recorte 2D, por uma cortadora a laser.

\section{Salão de Atos (FDM)}

A prototipagem rápida FDM é um processo aditivo baseado em sólido, que funciona a partir da fusão de um cartucho de ABS por um laser, um cabeçote de extrusão e o depósito do material sobre uma mesa de prototipagem.

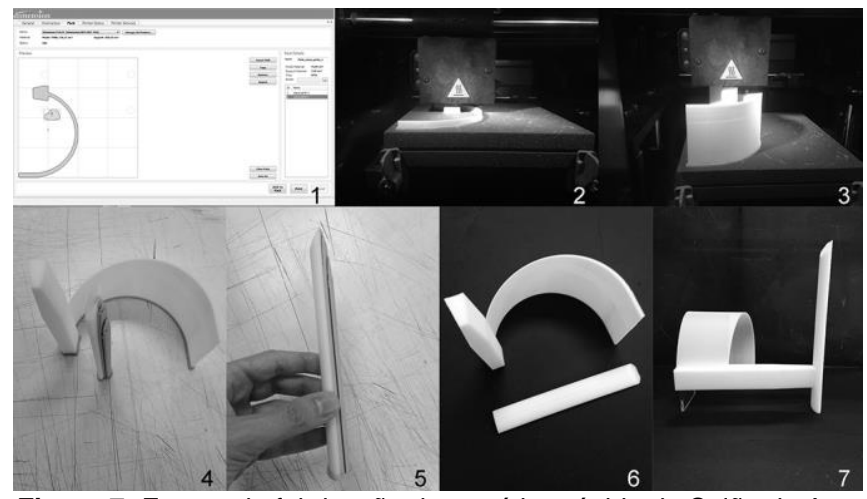

Figura 7: Etapas da fabricação do protótipo rápido do Salão de Atos pelo processo FDM. Fonte: Veiga (2016).
Foi prototipado um modelo referente à metade do edifício do Salão de Atos. Para que a impressora não criasse suportes excessivos, o modelo do Rhinoceros foi dividido em duas partes: casca + viga e pilar.

O tempo de prototipagem foi de 8h56. Observam-se na Figura 7 os diversos procedimentos da fabricação do protótipo: a visualização do protótipo no software da impressora (1); a peça sendo prototipada dentro da câmara de prototipagem da impressora (2 e 3); as peças após a impressão (4); o suporte em cinza ao longo do pilar (5); as peças livres de suportes (6) e o protótipo montado, na escala $1: 200(7)$.

\section{Biblioteca (SLS)}

A fabricação pela impressora de tecnologia SLS possibilitou a criação do protótipo mais preciso desta pesquisa.

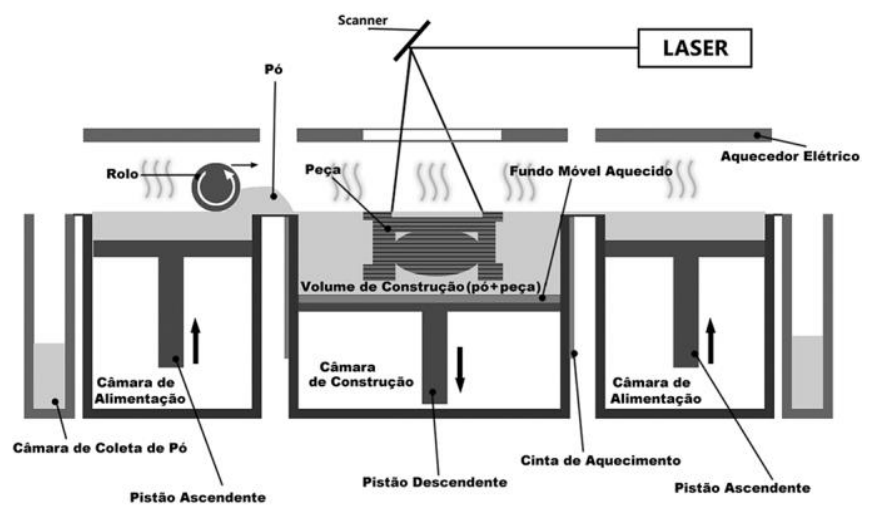

Figura 8: Etapas do funcionamento do Processo de Fabricação SLS. Fonte: CTI Renato Archer, Marcelo Fernandes de Oliveira (2012).

Esse procedimento funciona da seguinte maneira: um tanque circular é preenchido com pó de poliamida; um pistão na base do tanque empurra o pó para cima, fazendo com que o material caia no tanque principal de prototipagem com um diâmetro de $25,4 \mathrm{~cm}$ e uma altura de $33 \mathrm{~cm}$; na sequência, um rolo nivela o material e o sistema de varredura percorre a superfície do tanque, sinterizando uma camada de até 0,5 $\mathrm{mm}$ de espessura; um pistão sob o tanque principal desce no eixo Z; um incremento de pó da mesma espessura da anterior é adicionado e o processo se repete até que a peça inteira seja prototipada. As etapas do funcionamento podem ser observadas na Figura 8.

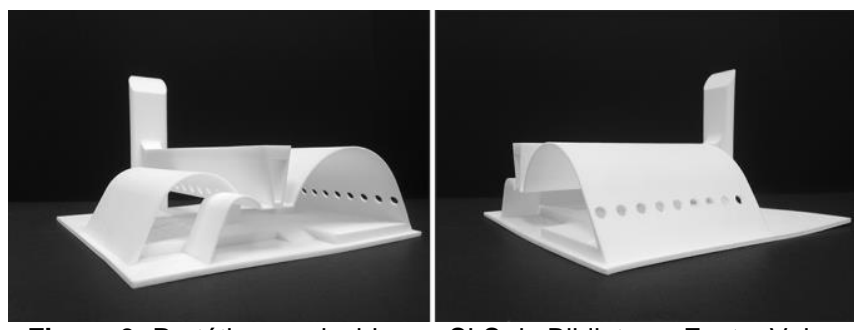

Figura 9: Protótipo produzido por SLS da Biblioteca. Fonte: Veiga (2016). 
A grande vantagem de se trabalhar com a tecnologia SLS é a possibilidade de se criar geometrias complexas sem a necessidade de suportes. O protótipo da Biblioteca em escala 1:200, observado na Figura 9, possui dimensões milimétricas, a espessura da cobertura se aproxima de 1 $\mathrm{mm}$. A tensão gerada na peça pela remoção manual dos suportes acarretaria em uma provável ruptura do modelo.

A precisão da prototipagem permite observar detalhes construtivos como o caixão perdido da viga aporticada, a pequena espessura da casca de concreto e as relações entre a forma externa e o espaço arquitetônico.

\section{Auditório (CNC + Cortadora a Laser)}

A fresadora CNC opera por remoção de material, portanto um processo subtrativo. Essa máquina opera em duas etapas: desbaste, onde a maior parte do material é removido; e acabamento, onde os detalhes são esculpidos pela máquina.
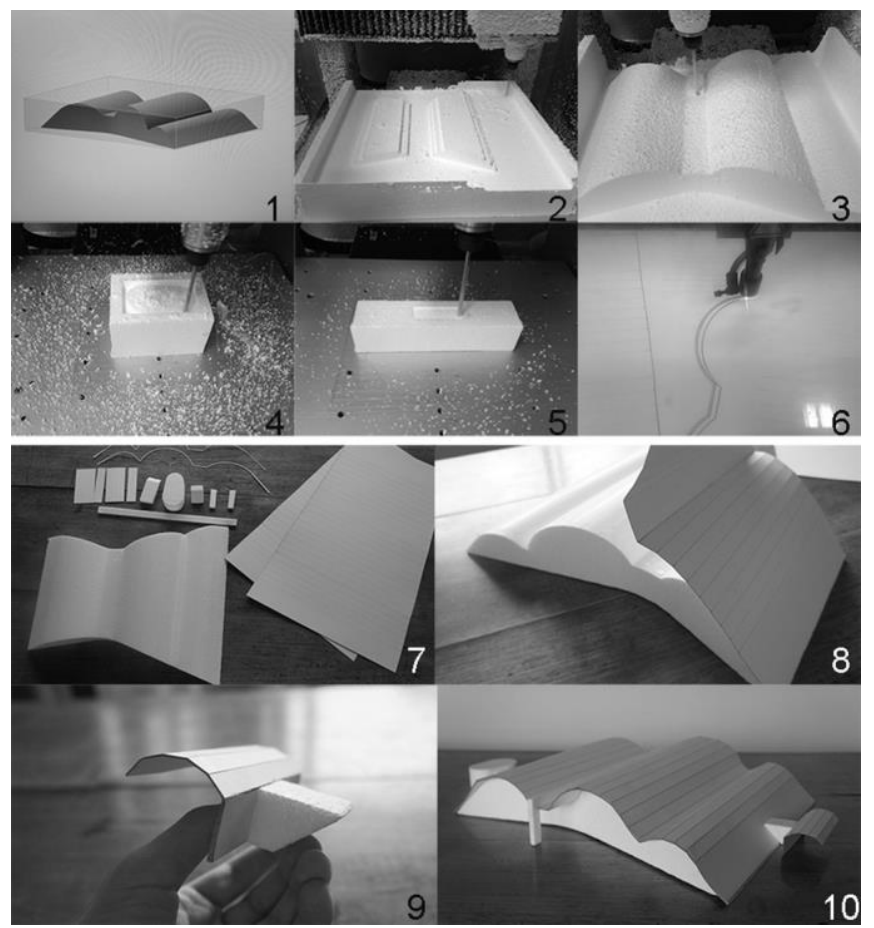

Figura 10: Procedimentos de fabricação do modelo do Auditório. Fonte: Veiga (2016).

A fresadora utilizada (Roland MDX - 540) possui três eixos ( $\mathrm{X}, \mathrm{Y}$ e Z) e o cabeçote da máquina só se move verticalmente, o que impediu que a ferramenta esculpisse lateralmente o bloco de isopor utilizado.

Sendo assim, o modelo foi prototipado na CNC em seis partes: i) o volume central do edifício; ii) a saída de emergência e seu iii) corredor de acesso; iv) a viga; v) os pilares vi) e o corredor de acesso ao edifício.

Devido à grande rotação da fresadora e a pequena dimensão na escala 1:200 das cascas de cobertura e da marquise da entrada, a fabricação na CNC não foi sucedida. Portanto, esses dois elementos foram fabricados na cortadora a laser e depois montados com as outras partes de isopor.

O processo de fabricação demorou 3h39. A Figura 10 exibe os diferentes procedimentos de fabricação e montagem do modelo físico do Auditório:

A visualização do volume central do edifício no software da fresadora (1); a fabricação do volume central em fase de desbastamento (2) e acabamento (3); a fabricação do bloco da saída de emergência (4); a fabricação dos pilares (5); o laser da cortadora cortando uma folha de papel tipo triplex, para a fabricação das cascas (6); as peças fabricadas e cortadas lado a lado (7); a colagem da casca cortada no laser com o volume fabricado na CNC (8 e 9) e o protótipo finalizado (10).

\section{Discussão}

A modelagem paramétrica auxiliou na identificação dos princípios geométricos adotados pelo arquiteto e também na definição, enquanto a modelagem geométrica possibilitou a definição da forma de elementos mais simples e a análise do espaço arquitetônico.

Os cortes técnicos bidimensionais foram excelentes fontes para identificar as diferentes alturas e estruturas dos variados elementos que compõe a forma. São ótimos métodos de visualização da forma construída. Nos cortes gerados pela modelagem paramétrica, o que se busca é a relação do edifício com seu espaço interno e seus vazios internos. É um método que nesse caso se apropriou do estudo dos espaços vazios ao invés da forma construída.

Durante a produção de modelos físicos provenientes das técnicas de fabricação digital, foi possível constatar que a materialidade revela de imediato aquilo que o desenho não permite transmitir com a mesma intensidade. Mesmo diante de variados tipos de desenhos, os protótipos rápidos conseguem complementar a compreensão da forma e do espaço concebidos pelo arquiteto.

Os processos aditivo e subtrativo apresentaram diferentes vantagens e desvantagens para a interpretação das obras analisadas. O processo subtrativo auxiliado pela fresadora CNC possibilitou a fabricação dos modelos de maior dimensão desta pesquisa. Devido à falta de mais eixos na fresadora, à alta rotatividade da fresa e ao material empregado, os modelos fabricados, especialmente os volumétricos, são ideais para o estudo da forma externa dos edifícios.

O processo aditivo com o uso da tecnologia SLS produziu protótipos monolíticos, com qualidade de impressão superior aos outros modelos fabricados, sem a necessidade de suportes, o que possibilitou fabricar modelos de formas curvilíneas e complexas.

Embora necessite de apoios para estruturar a fabricação de modelos, a tecnologia FDM possui diversas vantagens: a 
qualidade da prototipagem, o acesso ao método de fabricação e a construção de peças esguias, possibilitando a prototipagem do interior de parte dos edifícios.

A análise de projetos de arquitetura por diferentes métodos, processos e técnicas auxiliou no dinamismo investigativo, ao passo que foi possível visualizar e materializar geometrias antes implícitas e ocultas nos variados desenhos técnicos.

Esses métodos de investigação projetual, tanto digital quanto físico, possibilitam ao arquiteto a percepção da forma por diferentes meios. Com essas novas tecnologias, se tornou possível a criação de novas formas mais complexas, que demandariam muita habilidade, paciência e destreza caso fossem fabricados por métodos manuais, além de possibilitar a percepção do espaço pelo toque físico.

A criação dos diferentes modelos pelos diferentes métodos de fabricação digital permitiu 0 entendimento do desenvolvimento das curvas das cascas de concreto dos projetos, relações entre curvas e tangentes, tão presentes na arquitetura do Memorial da América Latina, e relações entre pontos de apoio e espessura e estrutura, assim como na relação dos diferentes objetos estruturantes do projeto, como casca, vigas, pilares e coberturas.

\section{Agradecimentos}

Os autores agradecem o apoio financeiro do CNPq e do Fundo Mackpesquisa, a Fundação do Memorial da América Latina, os funcionários do Laboratório de Prototipagem da Faculdade de Arquitetura e Urbanismo da Universidade Presbiteriana Mackenzie e Marcelo Fernandes de Oliveira do Centro de Tecnologia da Informação Renato Archer.

\section{Referências}

Corona, E. (2001). Oscar Niemeyer: uma lição de arquitetura. São Paulo: FUPAM.

Hudson, R. (2010). Strategies for parameric design in architecture. an application of practice led research (Doctoral thesis). University of Bath, Bath, England.

Katinsky, J. R. (1990). Leituras de arquitetura, viagens, projetos. (Tese de livre docência em arquitetura). Universidade de São Paulo, São Paulo, Brasil.

Lemos, C. A. C. (2013). Da Taipa ao Concreto: Crônicas e ensaios sobre a memória da arquitetura e do urbanismo. São Paulo: Três Estrelas.

Mark, E., Gross, M. D., \& Goldschmidt, G. (2008). A Perspective on Computer Aided Design after Four Decades, In 26th international conference on Education in Computer-Aided Architectural Design in Europe (eCAADe), Antwerp, Sept 17-20, 2008. pp 169-178.

Mayer, R. (2003). A linguagem de Oscar Niemeyer. (Dissertação de mestrado em arquitetura). Universidade Federal do Rio Grande do Sul, Porto Alegre, Brasil.

Monedero, J. (2000). Parametric design: a review and some experiences. Automation in Construction, 9(4), 369-377.

Ohtake, R. (2007). Oscar Niemeyer. São Paulo: Publifolha.

Papadaki, S. (1950). The work of Oscar Niemeyer. New York: Reinhold.
Philippou, S. (2008). Oscar Niemeyer: Curves of Irreverence. New Haven, CT: Yale University Press.

Sass, L., Oxman, R. (2006). Materializing design: the implications of rapid prototyping in digital design. Design Studies, 27(3), 325355.

Seely, J. C. K. (2000). Digital Fabrication in the Architectural Design Process (Master's dissertation). Massachusetts Institute of Technology, Cambridge, MA, USA.

Segre, R. (2008). Oscar Niemeyer: 100 anos, 100 obras. São Paulo: Instituto Tomie Ohtake.

Schumacher, P. (2009). Parametricism: A New Global Style for Architectural and Urban Design. Architectural Design, 79(2), 1423.

Underwood, D. K. (2010). Oscar Niemeyer e o modernismo de formas livres no Brasil. São Paulo: Cosac \& Naify.

Valle, M. A. A. (2000). Desenvolvimento da Forma e Procedimentos de Projeto na Arquitetura de Oscar Niemeyer (1935-1998) (Tese de doutorado em arquitetura). Universidade de São Paulo, São Paulo, Brasil.

Veiga, B. T. M. (2016). Oscar Niemeyer: modelagem paramétrica e fabricação digital de edifícios curvilíneos do Parque Ibirapuera e do Memorial da América Latina. (Dissertação de mestrado em arquitetura). Universidade Presbiteriana Mackenzie, São Paulo, Brasil.

Woodbury, R. (2010). Elements of Parametric Design. Abington: Routledge.

Zein, R. V. (2007). Três momentos de Oscar Niemeyer. São Paulo: Museu da Casa Brasileira. 